\title{
7) Genetico-clinical Typing of Progressive Muscular Dystrophy Based on Myoglobin Abnormality
}

\author{
Kazuo Miyoshi \\ Department of Internal Medicine, School of Medicine, \\ Tokushima University
}

In the previous papers, we reported that myoglobin $(\mathrm{Mb})$ in the Duchenne type of progressive muscular dystrophy (PMD) shows a unique abnormal pattern in its components, i. e. $\mathrm{Mb}_{1}$ decreased markedly and $\mathrm{Mb}_{3}$ increased concomitantly as compared with normal $\mathrm{Mb}$. The $\mathrm{Mb}$ content of remaining muscle fibers in atrophied muscles is kept on almost the same level of normal muscle. This abnormality of $\mathrm{Mb}$ is recognized only in male patients with the Duchenne type and partly in female gene carrier of this type, but never in other types of PMD, in the myopathies or neurogenic muscular atrophy.

On the basis of these facts we now assume that the etiology of PMD, especially that of the Duchenne type, is a myoglobinopathy and the pathogenesis is a chronic myolysis with partly myoregeneration.

The classification of PMD is to be settled basing on its genotype and the phenotype, i. e. clinical signs and symptoms related to the genotype.

Our classification of pure PMD is as follows, 1) Duchenne type (sex-linked recessive): common Duchenne type and benign Duchenne type (Becker), 2) Limb-girdle type (autosomal recessive): common limb-girdle type and malignant limb-girdle type (Miyoshi, K. et al.), 3) Facioscapulohumeral type (autosomal dominant), 4) Congenital muscular dystrophy, 5) Distal myopathy, 6) Ocular myopathy and 7) Cardiopathic muscular dystrophy (Norris, F. H. et al).

The malignant limb-girdle type (checked by the present authors) is characterized by similar clinical entity to the Duchenne type (main atrophy of pelvic muscles, early onset and malignant progress) and autosomal recessive heredity with an appearance of half and half in male and female. This type can be differentiated from the Duchenne type by the absence of $\mathrm{Mb}$ abnormality. About one out of 5 or 6 cases of limb-girdle type belongs to this type. 